\title{
Predictors of stillbirth among HIV-infected Tanzanian women
}

\section{Citation}

Kupka, Roland, Tarik Kassaye, Elmar Saathoff, Ellen Hertzmark, Gernard I. Msamanga, and Wafaie W. Fawzi. 2009. Predictors of Stillbirth Among HIV-Infected Tanzanian Women. Acta Obstet Gynecol Scand 88, no. 5: 584-592. doi:10.1080/00016340902835901.

\section{Published Version}

doi:10.1080/00016340902835901

\section{Permanent link}

http://nrs.harvard.edu/urn-3:HUL.InstRepos:32303184

\section{Terms of Use}

This article was downloaded from Harvard University's DASH repository, and is made available under the terms and conditions applicable to Other Posted Material, as set forth at http:// nrs.harvard.edu/urn-3:HUL.InstRepos:dash.current.terms-of-use\#LAA

\section{Share Your Story}

The Harvard community has made this article openly available.

Please share how this access benefits you. Submit a story.

\section{Accessibility}


Published in final edited form as:

Acta Obstet Gynecol Scand. 2009 ; 88(5): 584-592. doi:10.1080/00016340902835901.

\title{
Predictors of stillbirth among HIV-infected Tanzanian women
}

\author{
Roland Kupka $^{1,2}$, Tarik Kassaye ${ }^{3}$, Elmar Saathoff ${ }^{4}$, Ellen Hertzmark ${ }^{5}$, Gernard I. \\ Msamanga $^{6}$, and Wafaie W. Fawzi ${ }^{1,5}$ \\ ${ }^{1}$ Department of Nutrition, Harvard School of Public Health, Boston, MA, USA \\ 2United Nations Children's Fund, Regional Office for West and Central Africa, Dakar, Senegal \\ 3Unaffiliated \\ ${ }^{4}$ Department of Infectious Diseases and Tropical Medicine, University of Munich, Munich, Germany \\ ${ }^{5}$ Department of Epidemiology, Harvard School of Public Health, Boston, MA, USA \\ ${ }^{6}$ Department of Community Health, Muhimbili University of Health and Allied Sciences, Dar es \\ Salaam, Tanzania
}

\begin{abstract}
Objective-To determine maternal risk factors for stillbirth among pregnant HIV-infected women in sub-Saharan Africa.

Design-Prospective cohort study nested within a micronutrient trial. At enrollment, maternal sociodemographic, obstetric, immunologic, clinical, and nutritional variables were measured. Women were followed through monthly clinic visits until delivery. Multivariate predictors of stillbirth were identified in Poisson regression models.
\end{abstract}

Setting-Antenatal clinic in a tertiary care hospital in urban Dar es Salaam, Tanzania.

Population $-N=1,078$ women enrolled between 12 and 27 weeks of gestation.

Main outcome measures-Stillbirth (delivery of dead baby $\geq 28$ weeks' gestation), fresh stillbirth, and macerated stillbirth.

Results-Among 1,017 singleton pregnancies, there were 49 stillbirths, yielding a stillbirth risk of 50.0 per 1,000 deliveries $(95 \%$ Confidence Interval $(\mathrm{CI})=37.2,65.6)$. Of stillbirths with known type, $53.7 \%$ were fresh and $46.3 \%$ macerated. In multivariate analyses, baseline measures of late $(\geq 21$ weeks' gestation) study entry (Relative Risk $(\mathrm{RR})=2.13,95 \% \mathrm{CI}=1.17,3.87), \mathrm{CD} 3$ count $\geq 1,179$ cells $/ \mathrm{ml}(\mathrm{RR}=2.15,95 \% \mathrm{CI}=1.16,4.01)$, stillbirth history $(\mathrm{RR}=3.53,95 \% \mathrm{CI}=1.30,9.59)$, primiparity $(\mathrm{RR}=3.65,95 \% \mathrm{CI}=1.83,7.29)$, and syphilis infection $(\mathrm{RR}=2.06,95 \% \mathrm{CI}=1.09$,

\section{(C) 2009 Informa UK Ltd.}

Correspondence: Roland Kupka, UNICEF Regional Office for West and Central Africa, P.O. Box 29720, Dakar-Yoff, Senegal. rkupka@post.harvard.edu.

Publisher's Disclaimer: Full terms and conditions of use: http://www.informaworld.com/terms-and-conditions-of-access.pdf This article may be used for research, teaching and private study purposes. Any substantial or systematic reproduction, re-distribution, re-selling, loan or sub-licensing, systematic supply or distribution in any form to anyone is expressly forbidden.

The publisher does not give any warranty express or implied or make any representation that the contents will be complete or accurate or up to date. The accuracy of any instructions, formulae and drug doses should be independently verified with primary sources. The publisher shall not be liable for any loss, actions, claims, proceedings, demand or costs or damages whatsoever or howsoever caused arising directly or indirectly in connection with or arising out of the use of this material.

Clinical Trial Registration: ClinicalTrials.gov, www.clinicaltrials.gov, NCT00197743.

Declaration of interest: The authors report no conflicts of interest. The authors alone are responsible for the content and writing of this paper. The opinions and statements in this article are those of the author, and may not represent official UNICEF policies. 
3.88) predicted increased stillbirth risk. Late study entry, illiteracy, stillbirth history, primiparity, CD3 count $\geq 1,179$ cells $/ \mathrm{ml}$, gonorrhea infection, and previous hospitalization predicted increased risk of fresh stillbirth, while living alone and syphilis infection predicted increased risk of macerated stillbirth.

Conclusions-Applying antenatal screening and preventive tools for the socioeconomic, obstetric, immunologic, and clinical risk factors identified may assist in reducing the high incidence of stillbirth among HIV-infected women in urban sub-Saharan Africa.

\section{Keywords}

Predictors; pregnancy; HIV; stillbirth; Tanzania

\section{Introduction}

Worldwide, more than 3.3 million stillbirths occur each year. Developing countries account for over $97 \%$ of these deaths, while sub-Saharan Africa, the geographic region with the highest incidence of stillbirth in the world, contributes more than one-fourth to the worldwide total (1).

Maternal HIV infection may increase the risk of stillbirth (2). Given that 13 million women of reproductive age currently live with HIV in sub-Saharan Africa (3), HIV infection and its ramifications may account for a high toll of stillbirths. Nevertheless, little is known on predictors of stillbirth among HIV-infected women (4).

Moreover, no studies among HIV-infected women have comprehensively assessed etiologic factors separately for macerated stillbirths, which occur antepartum, and fresh stillbirths, which generally occur intrapartum. This separation is important, as the causes of endpoints may vary over the course of pregnancy (5). Inadequate access to vital obstetric care is an important risk factor for intrapartum stillbirth in sub-Saharan Africa (6), whereas chromosomal abnormalities, infection, and maternal demographic and behavioral factors may underlie antepartum stillbirths (7).

Identifying risk factors for stillbirth among HIV-infected women could inform specific preventive and curative actions during antenatal care (8). Therefore, we examined a wide range of maternal predictors of overall stillbirth risk, as well as of risks of macerated and fresh stillbirth, in a cohort of 1,017 HIV-infected Tanzanian women.

\section{Material and methods}

The study design has been described in detail (9). Study participants were HIV-infected pregnant women, presenting for the first prenatal visit between 12 and 27 weeks' gestation, were residents of Dar es Salaam, and intended to stay in the city until delivery and for a year thereafter. Those who gave informed consent to participate in the trial were randomized to a daily dose of one of the following regimens: (1) vitamin $A+\beta$-carotene ( $30 \mathrm{mg}$ of beta carotene $+5,000 \mathrm{IU}$ of preformed vitamin $\mathrm{A}$ ); (2) vitamins $\mathrm{B}, \mathrm{C}$, and $\mathrm{E}$ (20 $\mathrm{mg}$ of vitamin $\mathrm{B}_{1}, 20 \mathrm{mg}$ of vitamin $\mathrm{B}_{2}, 25 \mathrm{mg}$ of vitamin $\mathrm{B}_{6}, 100 \mathrm{mg}$ of niacin, $50 \mu \mathrm{g}$ of vitamin $\mathrm{B}_{12}, 500 \mathrm{mg}$ of vitamin $\mathrm{C}, 30 \mathrm{mg}$ of vitamin $\mathrm{E}$, and $0.8 \mathrm{mg}$ of folic acid); (3) vitamins $\mathrm{B}, \mathrm{C}$, and $\mathrm{E}+$ vitamin $\mathrm{A}+\beta$ carotene; or (4) placebo. Participants were enrolled from April 1995 to July 1997.

In accordance with national guidelines for antenatal care at the time, during pregnancy all women received $400 \mathrm{mg}$ of ferrous sulfate (equivalent to $120 \mathrm{mg}$ of ferrous iron) and folate (5 $\mathrm{mg}$ ) daily for anemia prophylaxis, and weekly doses of $500 \mathrm{mg}$ of chloroquine phosphate (equivalent to $300 \mathrm{mg}$ of chloroquine base) for malaria prophylaxis. Syphilis infection was 
treated with benzathine penicillin among women and their partners, while hypertension during pregnancy was treated with methyldopa. Antiretroviral therapy to reduce the risk of motherto-child transmission of HIV or to slow HIV disease progression was not available at the time of the study.

During the baseline visit, trained research nurses conducted structured interviews to collect information on obstetric history and sociodemographic factors such as age, literacy, education, marital status, living arrangements, and expenditure on food. They also collected information on history of morbidities, symptoms, and hospitalizations during the current pregnancy. The research staff aided women in the recollection of their date of last menstrual period. This date was used to calculate gestational age and season at conception. Study physicians carried out a complete medical examination and collected blood, urine, stool, and vaginal swab specimens. The stage of HIV disease was assigned in accordance to the World Health Organization (WHO) staging system (10). Trained nurses measured the women's blood pressure (to the nearest 1 $\mathrm{mmHg}$ ) and anthropometry. They measured height and mid-upper arm circumference to the nearest $0.1 \mathrm{~cm}$ and weight to the nearest $100 \mathrm{~g}$. Body mass index was calculated as weight $(\mathrm{kg}) /$ height $(\mathrm{m})^{2}$.

Study participants were followed during monthly visits to the clinic and were asked to deliver at Muhimbili National Hospital, where they received care in accordance with the national standard of care at the time.

\section{Laboratory methods}

Baseline specimens were used to determine the presence of HIV infection and levels of hemoglobin, T-lymphocytes (total lymphocytes; CD3, CD4, and CD8 subsets), serum retinol, serum vitamin $\mathrm{E}$, and erythrocyte sedimentation rate. At baseline, the presence of malaria, intestinal parasites, and sexually transmitted diseases was also determined.

HIV-1 serostatus was determined by ELISA (Well-cozyme, Murex Biotech. Ltd., Dartford, UK) and positive results were confirmed by the Western blot test (Bio-Rad Laboratories Ltd., Herfordshire, UK). Hemoglobin concentrations were measured by the CBC5 Coulter Counter (Coulter Corp., Miami, FL) or the cyanmethaemoglobin colorimetric method (Corning Inc., Corning, NY). Absolute counts of T-lymphocytes were quantified with the FACS count system (Becton-Dickinson, San Jose, CA). Serum retinol and vitamin E concentrations were determined with high performance liquid chromatography (HPLC), and erythrocyte sedimentation rate with the Westergren method.

Active syphilis was defined as positive results for sera antibodies in the Venereal Diseases Research Laboratory (VDRL) slide test (Murex Diagnostic, Dartford, UK) or the Treponema palladium hemag-glutination (TPHA, Fujirebio, Tokyo, Japan) test. Vaginal and cervical swabs were examined for infection by Neisseria gonorrhea, Candida albicans, and Trichomonas vaginalis. The presence of malaria parasites was ascertained from Giemsastained thick and thin smear blood films. The level of parasite density per cubic millimeter was estimated from the number of malarial parasites identified per 300 leukocytes and assuming a leukocyte count of $8,000 / \mathrm{mm}^{3}$ of blood. Stool specimens were examined for the presence of pathogenic protozoans and helminths. Macroscopic examinations were conducted for worms, whereas eggs, trophozites, and cysts were detected microscopically using saline and iodine wet mount, and the formalin-ether concentration technique.

\section{Outcome definitions}

Stillbirth was defined as the delivery of a dead baby $\geq 28$ weeks' gestation, in accordance with previous work in this setting $\left(9,{ }^{11}\right)$. Fresh stillbirths were characterized as death at birth without 
signs of skin disintegration or maceration; deaths with such signs were characterized as macerated stillbirths (12). Miscarriages (delivery <28 weeks' gestation) and live births born at $<28$ weeks' gestation were not in the risk set for stillbirths.

\section{Data analyses}

A total of 1,078 women participated in the parent multivitamin supplementation trial. Of the $1,041(97 \%)$ women with a known pregnancy outcome, the 1,017 (94.3\%) with singleton pregnancies constituted the study cohort.

Maternal predictors were evaluated at the baseline visit, which occurred between 12 and 27 weeks' gestation. Conventional cutoffs were used to categorize predictors; when these were not available, the median was used to classify variables, in line with previous publications by our group. Poisson regression models with robust variance were used to estimate relative risks and 95\% Confidence Intervals (CIs). Variables with univariate $p<0.2$ were included in multivariate regression models and retained if $p<0.05$. We used time-varying Cox proportional hazards models to determine whether predictors varied significantly between final models for fresh and macerated stillbirth.

Observations with missing data were kept in analyses using the missing indicator method (13). Given that the multivitamin regimen tested in the original trial significantly reduced the risk of stillbirth (9), we included an indicator variable for receipt of multivitamin trial regimen in all regression models. For stillbirth incidence, $95 \%$ CIs were calculated using exact methods for binomial proportions. Statistical significance was defined as $p<0.05$. Statistical analyses were performed using SAS software version 9.1 (SAS Institute Inc., Cary, NC).

The study was approved by the College Research and Publications Committee of Muhimbili University College of Health Sciences (now the Institutional Review Board at Muhimbili University of Health Sciences and Allied Sciences), the ethics committee of the National AIDS Control Program of the Tanzanian Ministry of Health, and the Institutional Review Board of the Harvard School of Public Health.

\section{Results}

On average, women were $24.7(\mathrm{SD}=4.8)$ years old and entered the study at $20.4(\mathrm{SD}=3.3)$ weeks' gestation (Table I). Primiparas comprised $36.5 \%$ of the cohort; among multiparas, $10.8 \%$ had a history of stillbirth. The mean CD4 cell count was $420(\mathrm{SD}=203)$ cells $/ \mathrm{mm}^{3}$ and most women $(80.6 \%)$ were at HIV Stage I. The prevalence of sexually transmitted diseases at baseline was $38.1 \%$.

Of the 1,017 singleton pregnancies, 49 resulted in stillbirths, yielding a stillbirth risk of 50.0 (95\% CI: 37.2, 65.6) per 1,000 deliveries (Figure 1). There were $22(44.9 \%)$ fresh stillbirths and 19 (38.8\%) macerated stillbirths; the timing was unknown for 8 (16.3\%). Among all stillbirths, $35(71.4 \%)$ were preterm and $14(28.6 \%)$ were term. The mean gestational age at birth was lower for stillbirths ( 34.4 weeks, $\mathrm{SD}=4.4)$ compared to livebirths ( 38.7 weeks, SD $=3.1)(p<0.0001)$.

In multivariate analyses examining risk factors for stillbirth, an approximately two-fold increased risk of stillbirth was noted among women with entry into the study $\geq 21$ weeks gestation, CD3 cell count $\geq 1,179$ cells $/ \mathrm{mm}^{3}$, and syphilis infection (Table II). Previous stillbirth and primiparity were related to approximately 3.5 -fold increased risks in comparison to multiparas without previous stillbirth. When macerated stillbirths were examined separately, not living with a partner and syphilis infection were identified as significant multivariate risk factors (Table III). In multivariate analyses for fresh stillbirth, significant risk factors were 
entry into the study $\geq 21$ weeks gestation, illiteracy, previous stillbirth, primiparity, CD3 cell count $\geq 1,179$ cells $/ \mathrm{mm}^{3}$, gonorrhea infection, and previous hospitalization during the same pregnancy (Table IV).

Time-varying analyses comparing predictors of macerated and fresh stillbirths also demonstrated that syphilis infection was a significant risk factor for macerated, but not fresh stillbirth $(p=0.05)$. There were no other significant interactions when comparing predictors for macerated stillbirth with those for fresh stillbirth.

\section{Discussion}

We assessed the incidence of stillbirth and its sociodemographic, obstetric, immunologic, clinical, and nutritional determinants among HIV-infected Tanzanian women. The risk of stillbirth among these women was 50 per 1,000 deliveries. This risk is higher than the aggregate risk for sub-Saharan Africa, estimated at 32 per 1,000 births, which is the highest of all regions in the world (14). HIV infection may account for this higher risk (2); however, risk of fetal loss (including both miscarriages and stillbirths) in the present study cohort did not differ from the risk in a contemporaneous cohort of HIV-uninfected women (15). The higher risk in our cohort may be due to better documentation than in population-based estimates, which are likely to underestimate the true risk of stillbirth (1).

In this cohort, $71.4 \%$ of stillbirths occurred before 37 weeks' gestation. Other studies support that the majority of stillbirths occur preterm (16). For instance, Chi et al. described that $66 \%$ of stillbirths occurred preterm in a multicenter study from sub-Saharan Africa among predominantly HIV-infected women (4). The proportion of fresh stillbirths in our study was four to five times higher than in developed countries, but was similar to that described by Chi et al. (4). The higher proportion of fresh stillbirths in sub-Saharan Africa is likely caused by deficiencies in care during delivery (7).

Late entry into the trial( $\geq 21$ weeks' gestation) was related to an increased risk of stillbirth overall and of fresh stillbirth. Women entered the trial after their first antenatal visit, so that entry into the trial is related to the duration of antenatal care. Thus, it appears that the duration of antenatal care was of benefit. Similarly, in a study from Brazil, fewer antenatal visits were related to an increased risk of stillbirth (17). Nevertheless, it is unclear whether the content of antenatal care was the causal factor for improved reproductive outcomes, or whether women who reported early represented a lower-risk group.

Illiteracy was related to increased risks of fresh stillbirth. Poor socioeconomic and educational status is associated with increased risk of stillbirth $\left(18,{ }^{19}\right)$, partly because women with low socioeconomic status are less likely to make use of antenatal care, even if it is officially free as in Tanzania (20).

Living without a partner was related to an increased risk of macerated stillbirth. In North America, pregnancy outcomes are poorer among single women compared to those who are married or unmarried but cohabiting (21). The underlying factors are unknown, but may relate to increased stress level during pregnancy, harmful behaviors during pregnancy, or poorer socioeconomic status among single women (21). These factors may also be at work in our setting.

Maternal syphilis infection at baseline was strongly related to stillbirths overall and to macerated but not fresh stillbirths. The causative agent, T. pallidum, may be transmitted to the fetus transplacentally and may decrease blood flow to the fetus (22). However, we were unable to perform placental assessments and, therefore, unable to confirm these mechanisms. Up to half of all stillbirths may be due to syphilis among unscreened women in Tanzania, and 
treatment for serological syphilis during pregnancy can reduce the risk of adverse pregnancy outcomes to that of seronegative women (23). It is unclear why syphilis infection remained predictive of macerated stillbirth in our study despite the availability of treatment. One possible explanation is that fetal infection had already occurred by the time women were recruited into the study; alternatively, some women may have reacquired the infection after the initial treatment.

Gonorrhea infection was related to fresh stillbirth in this study. This infection is generally not considered to be a risk factor for abortion and stillbirth; however, gonorrhea has been associated with prematurity and low birth weight (24). Our findings indicate that gonorrhea infection may also be a risk factor for fresh stillbirth among HIV-infected women, but the number of endpoints to examine this association was small.

A history of stillbirth was a strong risk factor for stillbirth. This is in line with evidence from different settings that describe a strong disposition to repeat adverse reproductive outcomes (16). Primiparity was a risk factor of similar magnitude. Possibly, primiparous women are less aware to detect warning signs during pregnancy. In North America, improved access to and quality of antenatal as well as obstetric care has reduced the risk of reproductive failure among primiparous women to that of multiparous women (25). In our setting, primiparity and a history of reproductive failure should trigger special attention during antenatal care while care overall improves.

Elevated CD3 cell count was related to increased risks of stillbirth overall and of fresh stillbirth. The CD3 complex is expressed on CD4 and CD8 cells as well as their immature precursor cells (26). Higher CD3 cell counts may suggest prior exposure to infectious agents or advanced stage of HIV disease, which may result in a higher risk of stillbirth. The lack of association between stillbirth and other markers of advanced HIV disease stage, such as elevated CD8 cell count or reduced CD4 count, does not support an association between advanced disease stage and stillbirth, though. Chance may therefore serve as an alternative explanation of the observed association.

Malarial infection at baseline was not related to risk of stillbirth. Malaria infection during pregnancy increases the risk of preterm delivery and low birth weight $\left(27,{ }^{28}\right)$, but only active placental malaria appears to increase the risk of stillbirth (29). Even though HIV infection increases the risk of malaria during pregnancy (30), our findings are in line with other evidence that maternal malaria does not independently predict reproductive failure.

Maternal anemia early in pregnancy is related to increased risks of low birth weight and prematurity among HIV-uninfected women (31) and may also increase stillbirth risk (32). There is little evidence from HIV-infected populations, and our current analyses indicate that maternal anemia in the first two trimesters is not predictive of fetal loss.

We described high risks of reproductive failure in this cohort of HIV-infected pregnant and we were able to identify maternal risk factors not only for macerated stillbirth, which have traditionally been related to pregnancy complications or maternal disease, but also for fresh stillbirth. In particular, our results indicate that among HIV-infected women from sub-Saharan Africa, improving intrapartum care needs renewed attention and that initiation of antepartum care in the first half of pregnancy may be beneficial. Our findings support the benefit of improving maternal immunologic status and the prevention and treatment of syphilis and gonorrhea for pregnancy outcomes. Implementing these interventions into antenatal care may reduce the unacceptably high incidence of stillbirths among HIV-infected women in subSaharan Africa. 


\section{Acknowledgments}

The study was supported by a grant from the National Institute of Child Health and Human Development (NICHD R01 32257).

\section{References}

1. World Health Organization. Neonatal and perinatal mortality: country, regional and global estimates. Geneva, Switzerland: WHO Press; 2006.

2. Brocklehurst $P$, French R. The association between maternal HIV infection and perinatal outcome: a systematic review of the literature and meta-analysis. Br J Obstet Gynaecol 1998;105:836-848. [PubMed: 9746375]

3. UNAIDS. AIDS epidemic update. Geneva, Switzerland: UNAIDS; 2007.

4. Chi BH, Wang L, Read JS, Taha TE, Sinkala M, Brown ER, et al. Predictors of stillbirth in sub-Saharan Africa. Obstet Gynecol 2007;110:989-997. [PubMed: 17978109]

5. McClure EM, Nalubamba-Phiri M, Goldenberg RL. Stillbirth in developing countries. Int J Gynaecol Obstet 2006;94:82-90. [PubMed: 16730726]

6. Ronsmans C, De Brouwere V, Dubourg D, Dieltiens G. Measuring the need for life-saving obstetric surgery in developing countries. Br J Obstet Gynaecol 2004;111:1027-1030.

7. Kramer MS, Liu S, Luo Z, Yuan H, Platt RW, Joseph KS. Analysis of perinatal mortality and its components: time for a change? Am J Epidemiol 2002;156:493-497. [PubMed: 12225996]

8. Goldenberg RL, Goepfert AR, Ramsey PS. Biochemical markers for the prediction of preterm birth. Am J Obstet Gynecol 2005;192:S36-S46. [PubMed: 15891711]

9. Fawzi WW, Msamanga GI, Spiegelman D, Urassa EJ, McGrath N, Mwakagile D, et al. Randomised trial of effects of vitamin supplements on pregnancy outcomes and T cell counts in HIV-1-infected women in Tanzania. Lancet 1998;351:1477-1482. [PubMed: 9605804]

10. World Health Organization. Proposed 'World Health Organization staging system for HIV infection and disease': preliminary testing by an international collaborative cross-sectional study. The WHO International Collaborating Group for the Study of the WHO Staging System. AIDS 1993;7:711718. [PubMed: 8100422]

11. Fawzi WW, Msamanga GI, Urassa W, Hertzmark E, Petraro P, Willett WC, et al. Vitamins and perinatal outcomes among HIV-negative women in Tanzania. N Engl J Med 2007;356:1423-1431. [PubMed: 17409323]

12. Wigglesworth JS. Monitoring perinatal mortality. A patho-physiological approach. Lancet 1980;2:684-686. [PubMed: 6106794]

13. Miettinen, O. Theoretical epidemiology. New York: John Wiley \& Sons; 1985.

14. Stanton C, Lawn JE, Rahman H, Wilczynska-Ketende K, Hill K. Stillbirth rates: delivering estimates in 190 countries. Lancet 2006;367:1487-1494. [PubMed: 16679161]

15. Coley J, Msamanga G, Smith Fawzi M, Kaaya S. The association between maternal HIV-1 infection and pregnancy outcomes in Dar es Salaam, Tanzania. Br J Obstet Gynaecol 2001;108:1125-1133.

16. Cnattingius S, Stephansson O. The epidemiology of stillbirth. Semin Perinatol 2002;26:25-30. [PubMed: 11876563]

17. Ferraz EM, Gray RH. A case-control study of stillbirths in northeast Brazil. Int J Gynaecol Obstet 1991;34:13-19. [PubMed: 1671015]

18. Stephansson O, Dickman PW, Johansson AL, Cnattingius S. The influence of socioeconomic status on stillbirth risk in Sweden. Int J Epidemiol 2001;30:1296-1301. [PubMed: 11821332]

19. Chen J, Fair M, Wilkins R, Cyr M. Fetal and Infant Mortality Study Group of the Canadian Perinatal Surveillance System. Maternal education and fetal and infant mortality in Quebec. Health Rep 1998;10:53-64. (Eng); 57-70 (Fre). [PubMed: 9842491]

20. Gazmararian JA, Arrington TL, Bailey CM, Schwarz KS, Koplan JP. Prenatal care for low-income women enrolled in a managed-care organization. Obstet Gynecol 1999;94:177-184. [PubMed: 10432123]

21. Luo ZC, Wilkins R, Kramer MS. Disparities in pregnancy outcomes according to marital and cohabitation status. Obstet Gynecol 2004;103:1300-1307. [PubMed: 15172868] 
22. Goldenberg RL, Thompson C. The infectious origins of stillbirth. Am J Obstet Gynecol 2003;189:861-873. [PubMed: 14526331]

23. Watson-Jones D, Gumodoka B, Weiss H, Changalucha J, Todd J, Mugeye K, et al. Syphilis in pregnancy in Tanzania. II. The effectiveness of antenatal syphilis screening and single-dose benzathine penicillin treatment for the prevention of adverse pregnancy outcomes. J Infect Dis 2002;186:948-957. [PubMed: 12232835]

24. Donders GG, Desmyter J, De Wet DH, Van Assche FA. The association of gonorrhoea and syphilis with premature birth and low birth-weight. Genitourin Med 1993;69:98-101. [PubMed: 8509101]

25. Fretts RC, Schmittdiel J, McLean FH, Usher RH, Goldman MB. Increased maternal age and the risk of fetal death. N Engl J Med 1995;333:953-957. [PubMed: 7666913]

26. Rabson A. Enumeration of T-cells subsets in patients with HIV infection. AIDS Clin Care 1995;7:13. [PubMed: 11362161]

27. Steketee RW, Wirima JJ, Slutsker L, Heymann DL, Breman JG. The problem of malaria and malaria control in pregnancy in sub-Saharan Africa. Am J Trop Med Hyg 1996;55:2-7. [PubMed: 8702033]

28. McGregor IA. Epidemiology, malaria and pregnancy. Am J Trop Med Hyg 1984;33:517-525. [PubMed: 6383091]

29. Watson-Jones D, Weiss HA, Changalucha JM, Todd J, Gumodoka B, Bulmer J, et al. Adverse birth outcomes in United Republic of Tanzania - impact and prevention of maternal risk factors. Bull World Health Org 2007;85:9-18. [PubMed: 17242753]

30. Verhoeff FH, Brabin BJ, Hart CA, Chimsuku L, Kazembe P, Broadhead RL. Increased prevalence of malaria in HIV-infected pregnant women and its implications for malaria control. Trop Med Int Health 1999;4:5-12. [PubMed: 10203167]

31. Scholl TO, Hediger ML. Anemia and iron-deficiency anemia: compilation of data on pregnancy outcome. Am J Clin Nutr 1994;59:492S-500S. discussion S-1S. [PubMed: 8304287]

32. Conde-Agudelo A, Belizan JM, Diaz-Rossello JL. Epidemiology of fetal death in Latin America. Acta Obstet Gynecol Scand 2000;79:371-378. [PubMed: 10830764] 


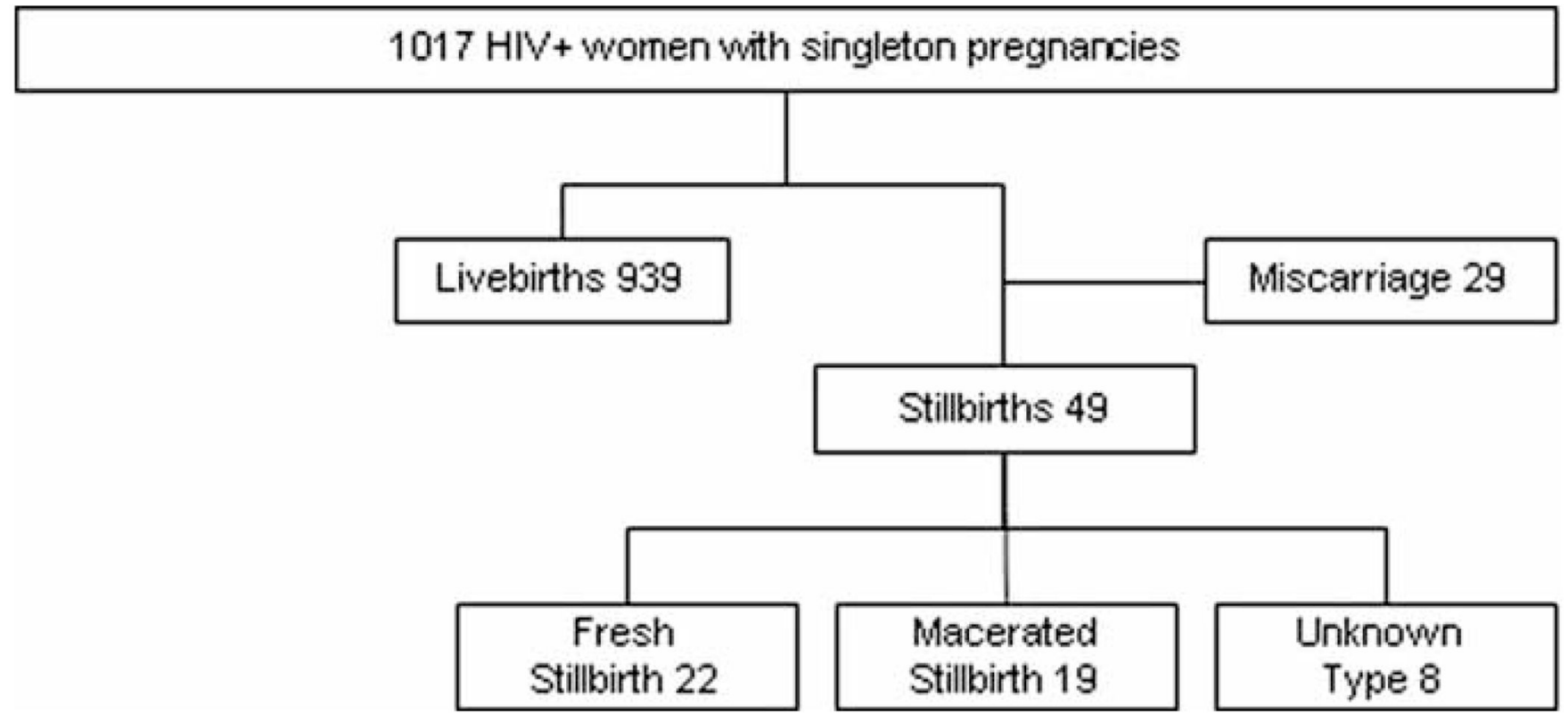

Figure 1.

Study profile. 
Table I

Background characteristics at baseline.

\begin{tabular}{|c|c|c|}
\hline Characteristic & $\begin{array}{r}\text { Women with } \\
\text { baseline data }(n)\end{array}$ & Mean (SD) or \% \\
\hline Age (years) & 1,017 & $24.7(4.8)$ \\
\hline $\begin{array}{l}\text { Gestational age at study } \\
\text { entry (weeks) }\end{array}$ & 1,017 & $20.4(3.3)$ \\
\hline Literacy (\%) & 1,012 & 91.6 \\
\hline Primiparity (\%) & 948 & 36.5 \\
\hline History of stillbirth (\%) ${ }^{a}$ & 631 & 10.8 \\
\hline CD4 cell count & 956 & $420(203)$ \\
\hline HIV stage $\geq 2(\%)$ & 1,015 & 80.6 \\
\hline $\begin{array}{l}\text { Presence of sexually } \\
\quad \text { transmitted disease }(\%)^{b}\end{array}$ & 985 & 38.1 \\
\hline Height (cm) & 1,001 & $156.6(5.9)$ \\
\hline $\begin{array}{l}\text { Mid-upper arm } \\
\text { circumference (cm) }\end{array}$ & 914 & $25.6(2.9)$ \\
\hline Hemoglobin (g/dl) & 999 & $9.4(1.7)$ \\
\hline
\end{tabular}

Acta Obstet Gynecol Scand. Author manuscript; available in PMC 2010 January 1. 


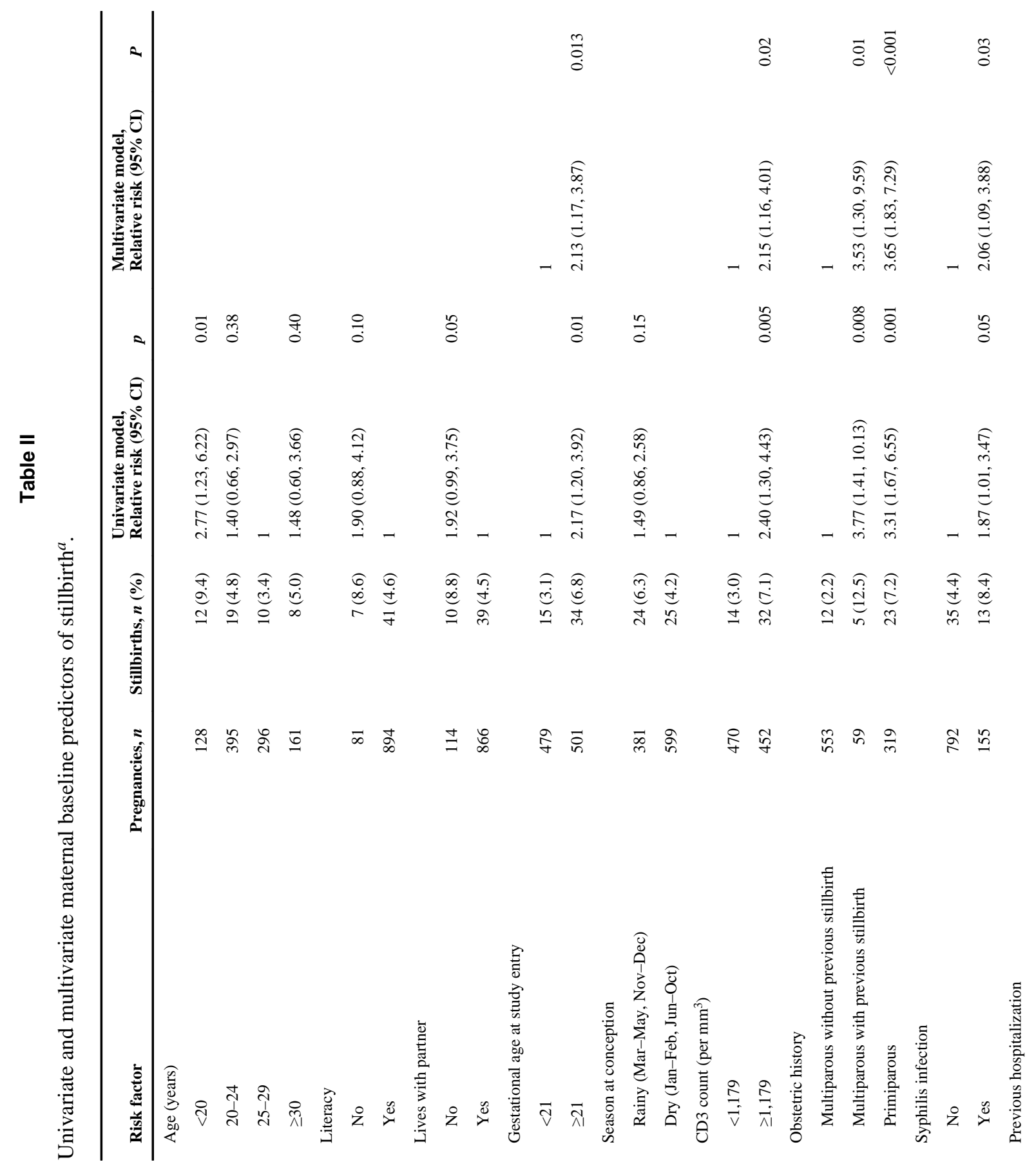




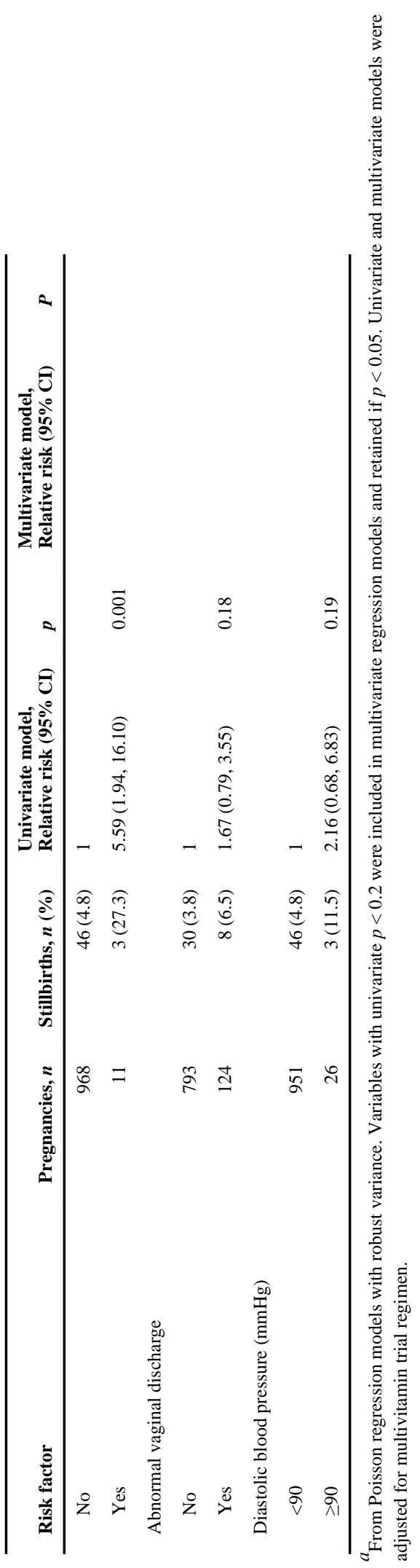

Acta Obstet Gynecol Scand. Author manuscript; available in PMC 2010 January 1. 


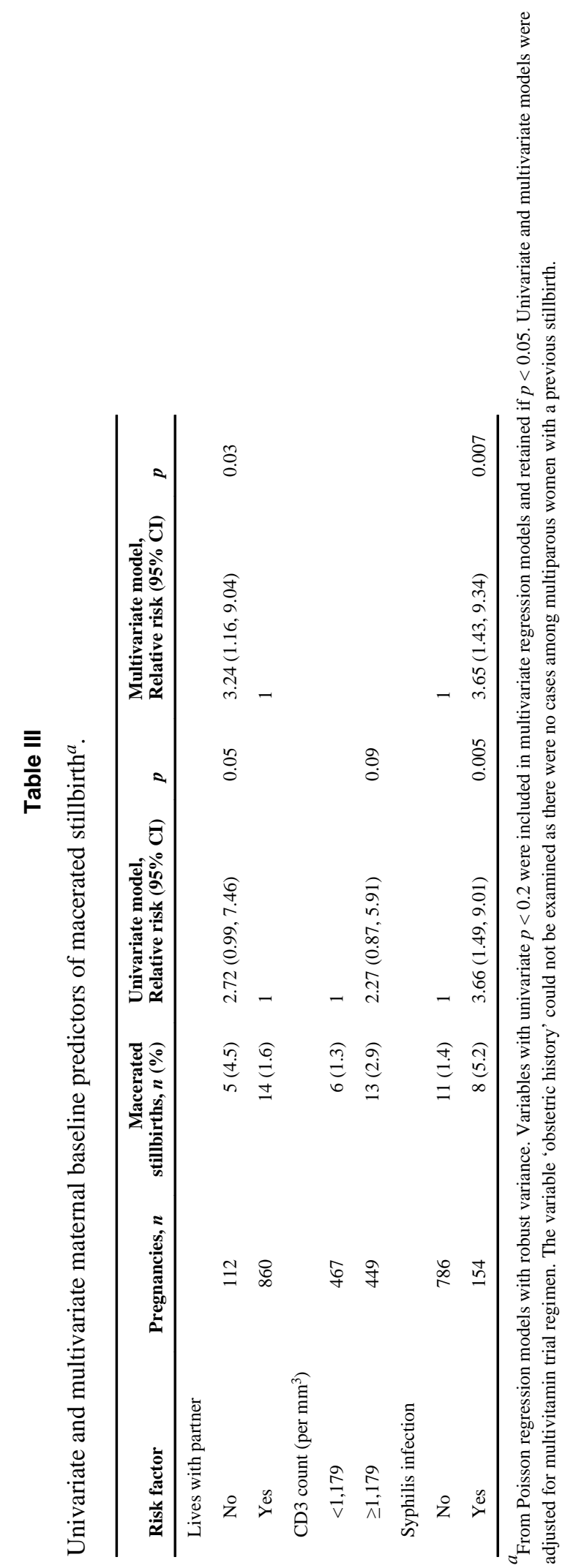

Acta Obstet Gynecol Scand. Author manuscript; available in PMC 2010 January 1. 


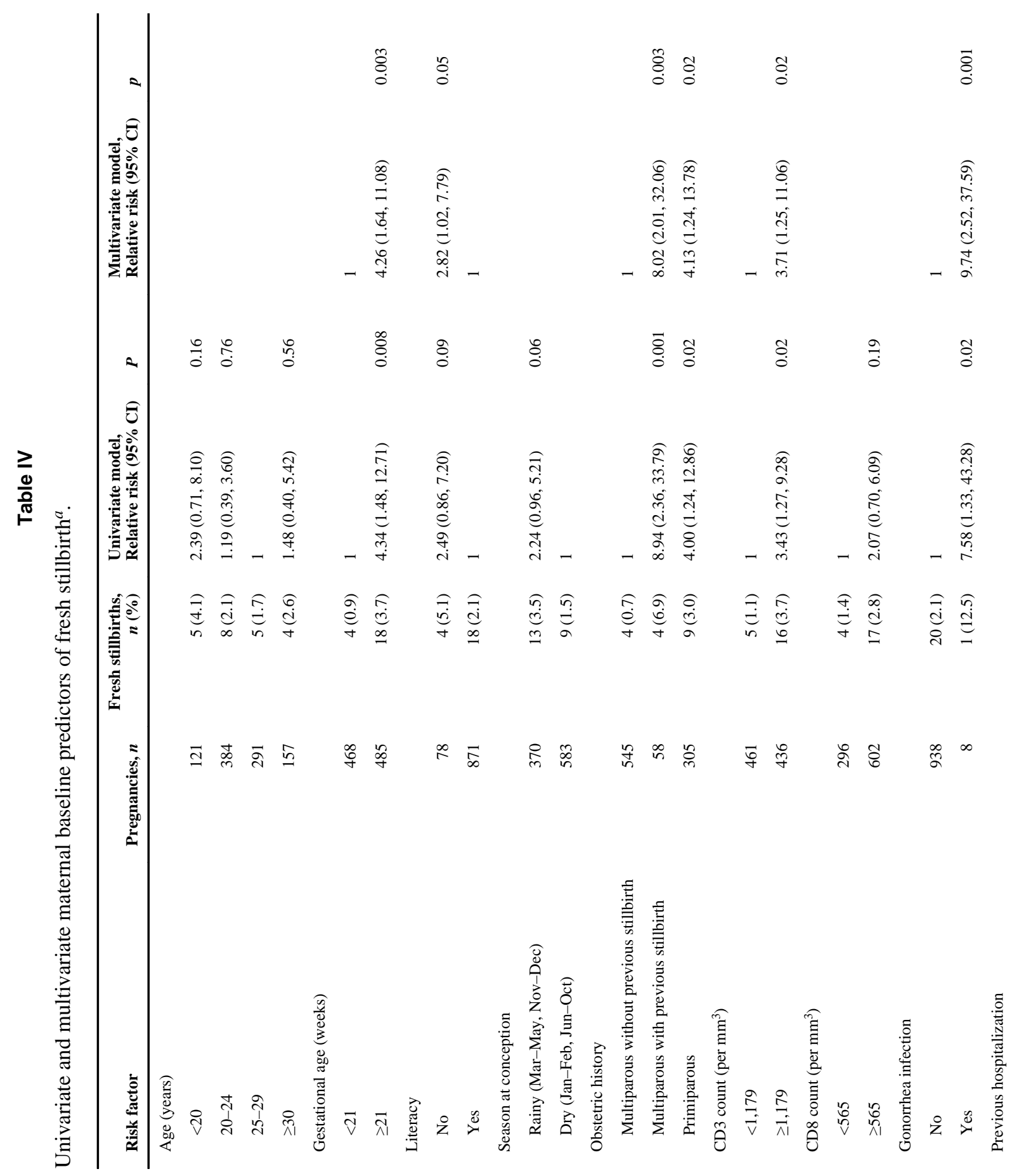




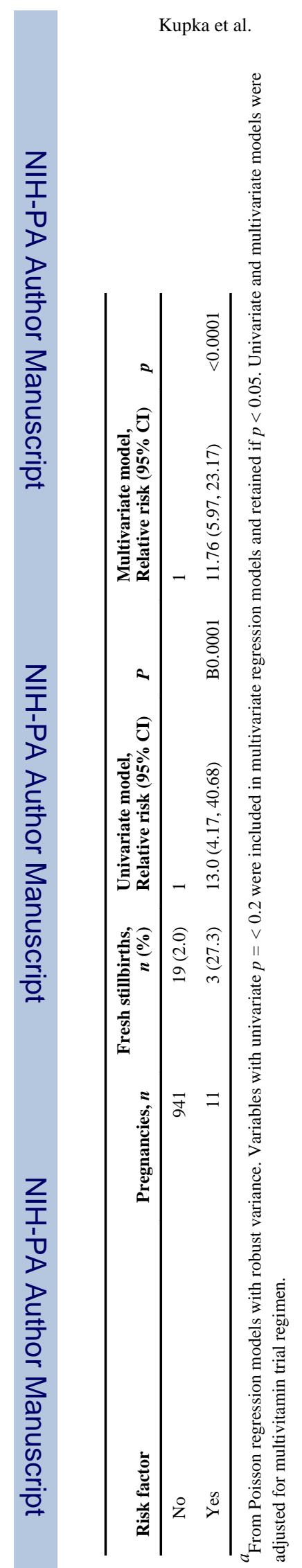

Page 15

Acta Obstet Gynecol Scand. Author manuscript; available in PMC 2010 January 1. 